\title{
Analysis on the Interest Equilibrium of Translation Subjects Under the "Belt and Road" Strategy
}

\author{
From the Perspective of Chinese Translators*
}

\author{
Shuang Wang \\ Fujian Jiangxia University \\ Fuzhou, China
}

\begin{abstract}
With the implementation of the "Belt and Road" strategy, China's cultural outreach in the countries along the line has accelerated significantly, but it still faces enormous cultural export barriers. In translation activities, there are various conflicts between material interests, political interests, and spiritual life interests among translation subjects along the line. Through the analysis of the complex game of translation subjects from the "Belt and Road" nations, this paper demonstrates the feasibility of cooperation and benefit of each participant. On this basis, this paper further proposes the winwin cooperation concept of translation subjects from the "Belt and Road" nations, so as to maximize the overall benefit of Nash equilibrium.
\end{abstract}

Keywords-the "Belt and Road"; translators; authors; readers; sponsors; game theory

\section{INTRODUCTION}

With the continuous advancement of China's the "Belt and Road" strategy, the scale of domestic professional translators and the need to promote the spread of Chinese culture and values will become increasingly mismatched. The China Translation Service Industry Analysis Report 2017 shows that the academic structure of employees of translation service companies is not directly proportional to their salary levels. Employees with a master's degree or above accounted for $52.2 \%$, but about half of the full-time staff's salary level is below the average social wage level. The high degree of education and low salary directly lead to the loss of professional translators, and the proportion of translators with a working life of less than 3 years is as high as $50 \%$.

From the comparison of the ratios of the numbers of professional translators and those of the total population between China and the United Kingdom, between China and the United States, the degree of specialization of personnel in the domestic translation industry is obviously behind. According to the data released by the China Translators

*Fund: This paper belongs to the project of the Fund Project. Fund Project type: "Fujian province Young and Middle-aged Teachers Education Scientific Research Project (College Special Project of Foreign Language Teaching Reform Research)"; Fund project number: JZ180084; Fund project name: Study on Behavioral Decision-Making Strategies of Translation Subjects from the Perspectives of Game Theory. Chinese chart classification number: $\mathrm{H} 315$
Association in September 2015, the individual members of the China Translation Association, including senior translators, expert members, members, honorary members and student members who were commended by the China Translation Association, total are 2180 people. In contrast, there are 800 individuals in the United States who only engage in judicial interpreters and translators in the judicial system. The British Translation Association has more than 3,000 professional translators for interpretation and translation. As shown in "Table I", the number of professional translators in China, compared with that in the United States and the United Kingdom is asymmetric with the total population. In particular, China (excluding Hong Kong, Macao, and Taiwan) has a total population of 22.4 times that of the UK, while the quantity ratio of professional translators is significantly lower than that of the UK.

TABLE I. COMPARISON OF THE TOTAL POPULATION OF THE UNITED STATES, CHINA AND THE UK, AND THE NUMBER OF PROFESSIONAL TRANSLATORS

\begin{tabular}{|l|l|l|}
\hline & \multicolumn{1}{|c|}{$\begin{array}{c}\text { Total population } \\
\text { ratio }\end{array}$} & $\begin{array}{c}\text { Professional } \\
\text { translators ratio }\end{array}$ \\
\hline Sino-America & $4.3: 1$ & $2.7: 1$ \\
\hline Sino-British & $22.4: 1$ & $0.7: 1$ \\
\hline
\end{tabular}

a. Source: Data compiled according to the China Translation Association (TAC) website, the National Association of Judicial Translators (NAJIT) website, the English Translation Association (ITI) website, and the World Population Network.

Translation is a social activity that includes both economic interests and spiritual wealth. The professionalism of translators is often positively correlated with the output of the two kinds of wealth. In the field of literatures translation, after domestic and foreign publishers have purchased copyright, it is difficult to find translators who are proficient in both cultures and literatures accomplishments due to differences in cultural backgrounds and reading habits between the East and the West, to realize the balance between reader preferences and the original "taste" of the works and abroad. Therefore, Chinese books will encounter many obstacles in the process of publishing abroad. Foreign publishers have received too little information on the Chinese literature market, and they do not understand the policies of Chinese book translation and publication1. In order to translate the "The Analects of Confucius" that is more acceptable to Westerners, the translation cost invested by Zhonghua Book [1]. 
Company is difficult to estimate, and the compensation for translation is also as high as $4 \%$ of the edition fee. According to the remuneration standard issued by the National Copyright Administration and the National Development and Reform Commission, translators generally do not take royalties in accordance with the royalty system, but the standard of remuneration for basic manuscripts and prints, ranging from tens to several hundred Yuan per thousand words.

\section{ThE TRANSLATION CONTEXT OF GAME THEORY}

Game theory, also known as strategy theory, studies the relationship and behavior between rational individuals in competition and cooperation. People keep choosing and making decisions. The direct influence of personal choices and decisions also depends on the decision-making results of others. This behavior of integrating other people's behavior choices or their own preferences for decision-making is the game [2]. Game theory studies assume that the subject of behavior is rational, so this interdisciplinary theoretical reference is the inevitable application of game theory to linguistics.

The translation context of game theory refers to the game behavior between multiple subjects in the translation process. The subject of translation, that is, the interests of the game, includes: author, translator, reader, sponsor, etc. Generate six pairs of game relationships: the relationship between authors and translators, authors and readers, authors and sponsors, translators and readers, translators and sponsors, readers and sponsors. If there is a binding agreement between the translation subjects, it is a cooperative game; on the contrary, if it does not exist, it is a non-cooperative game. Therefore, these six pairs of game combinations can be classified into the cooperative game - author and sponsor, translator and sponsor; and non-cooperative game - author and translator (including classic translation and non-classic translation), author and reader, translator and reader, reader and sponsor. However, the fact is that the translator and the other three participants can achieve the result of cooperation through an infinite number of repeated dynamic games. Therefore, this paper analyzes the game equilibrium among translation subjects from the perspective of long-term cooperation between translators and other subjects.

\section{GAME ANALYSIS OF TRANSLATORS AND OTHER TRANSLATION SUBJECTS}

The translation subjects are informal organizational relationships. The manifestation of externality is that there are multiple stakeholders, and the original author is outside the translation decision. Positive and negative externalities can be measured by the positive and negative benefits of successful or failed business, cultural, and political activities. "Benefits": including material, political, spiritual life and other aspects. The interests of game behavior include the material interests, political interests and spiritual wealth of the four translation subjects. The above is the purpose and significance of translation. The early translation behavior was conducted at the stage of "knowing the world" and integrating with the mainstream values of the West. At present, under the "Belt and Road" strategy, it has completely entered the stage of "letting the world know China."

\section{A. Game Analysis Between Translators and Sponsors}

Taking Chinese books translated into foreign languages as an example, most of the sponsors are Chinese and foreign publishers and agents. In the game of behavior based on the "economic man", the sponsor is any force that influences the literature works, such as agitation, propaganda, censorship and destruction. Sponsors may be individuals or groups, such as religious organizations, political parties, publishers, etc. The Sponsors' ideology determines the translator's ideology (whether or not the translator is willing), thus governing his most basic translation strategies and problem-solving methods [3]. From the cultural point of view of the works, the translator is in the position of information superiority; from the marketability of the works, the sponsor has a relative information advantage. Therefore, the game between the two sides is an incomplete information game (dynamic) game. At the same time, the game between the sponsor and the translator is also a cooperative game. Some of the agreements drafted in the actual translation activities can be enforced, and some cannot be enforced. The cooperative game with the goal of economic interests has the characteristics of incomplete information. The sponsor allows the translator to adopt certain methods, including guiding the reader's expectations or catering to the reader's tastes to enable the reader to accept the translation [4]. This paper uses the "Prisoner's Dilemma Game" to analyze the game relationship between the sponsor and the translator.

Hypothesis 1: The sponsor is the main provider of translation strategies.

Hypothesis 2: For economic benefit considerations and mastery of the readership information, the sponsor will make a choice that is "self-interested", including enforcing or not enforcing translators must use their prescribed translation strategies.

Hypothesis 3: The translator will consider the "benefiting me" choice for which the translated works can be recognized by the readers, and will make choices to cater to or guide the readers.

TABLE II. THE PAYMENT MATRIX OF THE PRISONER'S DILEMMA GAME BETWEEN THE SPONSOR AND THE TRANSLATOR

\begin{tabular}{|l|l|l|}
\hline Sponsors & Canslators & Guide \\
\hline Enforce & & \\
\hline Don't enforce & 2,2 & $-1,-2$ \\
\hline
\end{tabular}

"Table II" shows the utility values of the various choices made by sponsors and translators in different market environments. At the first quadrant, after sponsors make the market expectations and impose an enforcement strategy, if the translator adopts a strategy that caters to the reader, in addition to receiving the basic reward, it can also obtain weighted benefits, such as the reprint of the printed part. 2 
units of utility; similarly, the sponsor has obtained 2 units of utility in this market environment due to good market response. The second quadrant is under the same coercive strategy. Due to differences in ideology, the translator chooses to guide the reader to pay compensation because of violation of the contract. The translator can only obtain the utility of -2 units; the sponsor was dragged down and sold at a loss, gaining -1 unit utility. At the third quadrant, after the sponsor makes an expectation on the market and decides not to stipulate the translation strategy, if the translator chooses to cater to the reader, the market will be aesthetically fatigued. The lack of innovation in the translation results is denied by the sponsor, and it needs to be reworked or even required to be overdue compensation, getting -2 units of utility; sponsors get -1 unit utility. Under the same circumstances, in the fourth quadrant, the translator can use a more flexible translation strategy, and the translator and the sponsor also have to bear a certain risk cost, that is, fail to achieve the expected market reaction, then the result of the game is the sponsor. Both the translator and the translator get 1 unit of utility.

However, the game hypothesis of translation behavior is based on economic interests. It is undeniable that the "interests" generated by translation activities include not only material interests, but also political and spiritual life, especially in guiding the "Belt and Road" national readers culture aesthetics, realizing the exchanges between China and the different ideologies of the "Belt and Road" countries, the benign interaction between the translators creates enormous social and cultural values within the region.

\section{B. Game Analysis Between Translators and Readers}

Hypothesis 1: Translators and readers are rational economic people, and consider the maximization of their own interests when choosing strategies.

Hypothesis 2: The information of the translator and the reader is completely symmetrical, and they fully understand each other's and their own information.

Hypothesis 3: The translator's benefits include remuneration and reputation.

Participants: 1 represents the translator and 2 represents the reader.

The reader's strategy is divided into: approval or disapproval of the translator's expression and language style. That is, $\mathrm{S} 1$ = (approval, disapproval).

The translator's strategy is also divided into: approval or disapproval of the expression and language style that the reader can accept. That is, $\mathrm{S} 2=$ (approval, disapproval).

TABLE III. THE PAYMENT FUnCTION OF THE TRANSLATOR AND READER

\begin{tabular}{|l|l|l|}
\hline Translators & Approval & Disapproval \\
\hline Approval & P2-C2+H, P1-C1 & P'2-C2+H, P1-C1 \\
\hline Disapproval & P2-C2+D-H, P'1-C1 & P'2-C2+ D-H, P'1-C1 \\
\hline
\end{tabular}

As shown in "Table III", C1 is the money the reader pays for reading the translation. P1 is the reader's benefit: information and spiritual wealth that can be transformed into productivity. P' 1 is the feeling or utility of the reader when reading the translator's low-quality translation. It is generally considered that $\mathrm{P} 1>\mathrm{P}$ '1

$\mathrm{C} 2$ is the translator's cost input, including time cost and mental work. P2 is the remuneration income obtained by the translator corresponding to its input; $\mathrm{P}^{\prime} 2$ is the remuneration income obtained by the translator that does not correspond to its input, obviously $\mathrm{P} 2>\mathrm{P}^{\prime} 2 . \mathrm{H}$ is the social reputation of the translator after the translation is published. $\mathrm{D}$ is the time and cost of learning that the translator does not have a deep understanding of the reader's cultural background and reading habits.

For the translator, $\mathrm{P} 2 \max =\mathrm{P} 2-\mathrm{C} 2+\mathrm{H}$, the translator maximizes its own interests, and in the long run, high-quality, high-computation translation results can bring social reputation that money cannot be purchased, and will be very concerned. Similarly, the reader understands that the reader's interests can only be maximized if the translator has a full sense of expression that the reader can accept and the language style: $\mathrm{P} 1 \mathrm{max}=\mathrm{P} 1-\mathrm{C} 1$. Therefore, only the translator and the reader can achieve the win-win outcome of the cooperative game on the basis of mutual recognition.

\section{Game Analysis Between Translators and Authors}

In the game activities of the translation subjects, as long as there is a certain interest subject that does not fully understand some of the information of some stakeholders, and it does not fully grasp the benefit or benefit function of all stakeholders. This refers to the incomplete information environment of game theory. In the translation of classics, because the two subjects are often in different eras, compared with the era in which the author is located, the translator can't advance the writing level easily, and even the later translators can't actively achieve the game equilibrium. In the non-classic translation activities, due to the gap in the comprehensive quality of cultural knowledge and writing level, even if they live in the same era, the author and the translator have asymmetry in the information of the other party. And the fact that there is usually no contractual constraint between the translator and the author, so there is a non-cooperative game between the two subjects.

The revelation of Nash Equilibrium is that cooperation is a favorable self-interest strategy. Therefore, if the two subjects achieve a positive and negative game, that is, the interests of both sides of the game increase, or at least the interests of one party increase, while the interests of the other party are not damaged, and the overall interests will increase. With the development of social material civilization and spiritual civilization within the region, there will be more and more cooperation in the cultural field of the countries along the "Belt and Road".

Translation is a special kind of game behavior. While the parties "consciously or unconsciously abide by the social norms of the source language or the target language, their personal interests are always the primary factor to be 
considered. The so-called game actors are all "selfinterested". The dialogue between the author and the translator can achieve the understanding through direct or indirect communication or negotiation with each other, thus avoiding the misunderstanding caused by the stereotype of the translator or reader during the translation process, maximizing the protection of the interests of the translator and the author at the same time.

\section{FACTORS That AFFECT THE GAME BETWEEN THE TRANSLATOR AND OTHER TRANSLATION SUBJECTS}

\section{A. Cultural Soft Power}

The contemporary Chinese humanities and social sciences theory is still in the "apprenticeship" stage of "taking the West as a teacher". The most important shortage is the relative weakness of cultural soft power. This is more prominent in the long-term immersion of British and American languages and cultures. Recently, under the trend that the Korean culture has exerted a more and more extensive influence on the cultural industry in Asia and the world, foreign languages have become a weapon, and the interpersonal vision has become blurred once again. Translators tend to look up the cultural value and language logic of the source language with strong cultural soft power. The grammars and expressions of the languages translated into are often despised. For example, the words "big trend" and "real feeling" are translated literally by the translator, and no synonyms or similar expressions in Chinese are used. Although the readers or the audience can understand, it is inevitable to give people the suspicion of "flattering outside" and "crude". The language habits of younger speakers whose native language is translated are affected.

\section{B. Commercial Interests}

In order to maximize the pursuit of commercial interests, the main player of the game in the market economy environment - the sponsor must put the acceptance of the consumer who purchased the product in the most important position. The market response of the film and television works, commodities, etc. translated into the target language is often the first consideration for sponsors.

For example, the movie Speed is translated into "speed of life and death". Compared with "speed", it is easier for Chinese audiences to produce associations such as "life and death" and "lifeline", creating a sense of urgency, inspiring interest in watching movies, and meeting the sponsor's Interest orientation. Similar cases will be encountered when goods are placed in foreign markets. For example, "Black Toothpaste" entered the US market and was named after "DARKIE". It was confronted with protests against ethnic and human rights groups. Blacks believed that they were discriminated against and insulted, and they were emotionally unacceptable. For commercial interests, the company responded quickly to consumers' negative feedback, changing the trademark to "DARLIE".

The trademark of the famous snack "Tokie $\mathrm{Bu} \mathrm{Li"} \mathrm{in}$ Tianjin can't be directly translated with the corresponding
English words, and there is no way to apply the target language. Until 2008, Gobelieve was officially adopted as a registered trademark. It is not only pronounced very close to "dog ignored", but the meaning is also very good. It is consistent with the quality and the consistently advocated integrity service, consistent with its good business image [5].

\section{Egocentricism}

Focus on your own thoughts, or just talk about your own story, which will use a lot of energy that should be used to focus on communication partners [6]. This is reflected in the translation behavior as an absolute "profit for me", while neglecting the objective differences between the subjects, that is, the existence of differences in values, cultural background, education level. Under the "Belt and Road" strategy, the differences between countries along the "Belt and Road" should be respected in contemporary society with increasingly frequent intercultural communication. It is particularly important to make reasonable predictions and appropriate responses to such differences, such as achieving agreement on interests through negotiation.

\section{Political Attitudes}

The differences in political attitudes and the conflicts caused by such differences make the game behavior between the various subjects of the translation more complicated, sometimes it is difficult to negotiate successfully, and the conflicts remain and the contradictions are difficult to resolve. For example, Xi Jinping's "hard-working itself needs to be hard", due to different political perspectives, the Chinese, American and English translation circles have had a lot of controversy. The focus of the debate in the translation community is what does "self" mean? CNN, The New York Times and The Daily Telegraph have different understandings of "self" and have chosen different political positions. There are three different versions of the translation.

CNN: To forge iron, one must be strong.

New York Times: To forge iron, the body must itself be strong.

Daily Telegraph: To forge iron, you need a strong hammer.

All of the above three versions of translations view the Chinese Communist Party's governance of the party from the perspective of ordinary people or general objective angles, emphasizing external forces and factors other than "iron". At the meeting of the central leaders and reporters at the time, the on-site translation version was: To be turned into iron, the metal itself must be strong. To always be China's strong core of leadership, the Communist Party must be self-reliant and able to withstand tempering [7]. That is to say, standing in the position of the Communist Party of China shows the attitude of the party, and emphasizes the role that the "iron" itself needs to play.

\section{E. Stereotypes of the Source Language Culture}

In recent years, psychologists have given a formal definition of stereotypes: "Stereotype is a cognitive structure 
that includes the knowledge, beliefs, and expectations of some human social groups." 8Stereotype guides people to base their information, the way they disseminate information, and the acceptance of information on false assumptions [9]. For a long time, some Westerners have habitually had a superior sense of institutional construction, so that they are too esteemed by Western institutions, and it is easy to ignore the differences between the historical background and cultural concepts of the East and West.

Han Ruixiang, winner of Lu Xun's Literary Translation Award: "Many German readers always regard the most primitive, ignorant and cruelest things in Chinese contemporary literature as the root of Chinese image. The Germans' understanding of China still does not transcend political differences and Ideology has not given up their inherent Eurocentrism." Such works as Jia Pingwa's Shangzhou and Chen Zhongshi's White Deer, because German readers' understanding of Chinese contemporary literature is based on the inherent impression from China as a backward society and a developing country. It is difficult to find suitable partners in Germany to introduce these works. The literature works' promotion is influenced by the cultural barriers of the target countries. Under the influence of the buyer's market, the game with readers is often at a disadvantage.

\section{THE WIN-WIN STRATEGY OF TRANSLATORS AND OTHER TRANSLATION SUBJECTS UNDER THE "BELT AND ROAD" STRATEGY}

\section{A. Adhering to "Focus on Me"}

In the Chinese-English translation of sensitive issues involving national sovereignty, in order to maintain political stance and safeguard national sovereign dignity and national interests, the State Administration of Press, Publication, Radio, Film and Television has made uniform provisions on the translation of proper names such as the names of party and government organizations and place names. For example, the Nansha Islands must use the Chinese name, and cannot use the Spratly Islands to cater to the habits of foreign readers; the Diaoyu Islands, cannot be translated as Senkaku Islands [10].

In the process of Chinese culture going out, the industry should extensively explore and think about rhetoric, essays and literature-related politics, history, customs and other issues. At the same time, the education department should keep up with the pace of the country's "Belt and Road", strengthen the promotion and teaching of classical literature, gradually eliminate the Chinese people's separation of classics, and promote the classics, thus achieving cultural spillover effects from the inside out. Relevant departments should strengthen the construction of laws and regulations for the protection of intellectual property rights and provide policy guarantees for enhancing the soft power of Chinese culture.

\section{B. Diluting the Chinese Imprint}

In the game of the translation subjects, using the syntactic cues of the understanding strategy and the interpretation of the meaning, context, knowledge and experience clues, eliminating egocentricism, and appropriately diluting the Chinese imprint are wise choices to reduce the conflicts of interests between the translators and other subjects. Since speech activity is already a highly automated psychological activity, strategies are often used unconsciously in language understanding and are related to the habits of the speaker [11]. Using the Belt and Road countries to compare the way of speaking and language style to translate, fully examine the characteristics of the Belt and Road nations' reader market and the impression of Chinese culture, rather than the hard-to-consist the communication mode of Chinese characteristics, in order to make the translation The information conveyed has been widely accepted and spread in the cultural environment of the "Belt and Road" countries. Therefore, based on the establishment of good linguistic knowledge and cognitive experience of the world, the conflicts of interests between translators, readers and sponsors will be weakened. For example, the famous scholar Sha Boli's translation of Water Margin successfully broke the boundaries between Chinese and foreign languages, cultures and history, and became the best-selling English translation of Water Margin.

\section{Strengthening Coordination Management}

In addition, in order to effectively solve the information asymmetry between the translator and other translation subjects, and to ensure the Nash equilibrium of the translation subject game in the countries along the "Belt and Road", this paper suggests that relevant industry associations, such as the China Translation Association, assist the cultural management department to improve the coordination work for the translation subjects of the countries along the "Belt and Road" and to strengthen the industry's normative management, in order to effectively coordinate the policies and actions of the translation subjects of various countries, reduce cooperation friction and resistance.

\section{CONCLUSION}

Under the "Belt and Road" strategy, the games among translators, authors, readers and sponsors have already become cultural games in fact. It is the only win-win cooperation concept held by translation subjects that expand the cultural influence and promote the economic exchanges largely and further.

\section{REFERENCES}

[1] Bai Ye. Mo Yan Won the Nobel Prize and Caused Calm Thinking:Three Paths for Chinese Books [J]. Beijing Business Daily, 2012.11

[2] Xiang Mingyou, Xia Dengshan. A Review of Game Pragmatics [J] Shandong Foreign Language Teaching, 2011(4): 15

[3] Bassmett \& Lefevere A. Constructing Culture Essays on Literary Translation $[\mathrm{M}]$. Shanghai, Shanghai Foreign Language Education Press, 2001:48. 
[4] Wang Xiangling, Jiang Jiansong. On the Subjectivity of Translation to Intersubjectivity [J]. Journal of Foreign language, 2006(6): 107.

[5] Zhang Shunsheng. Three Basic Methods of English-Chinese Translation [J]. Chinese Translation, 2015(1): 52.

[6] Yan Wenbin. Interesting Discussion on Political Discourse Spreads to the Outside World [DB/OL]. (2015-09-23). http://www.taconline.org.cn/ch/tran/2015-09/23/content_8258744.htm

[7] Larry A. Samovar, Richard E. Porter, and Edwin R. McDaniel. Communication between Cultures $[\mathrm{M}]$. People's University Publication House, 2013, 5:314.

[8] C.S. Abbate, S. Boca, and P. Bocchiaro. Stereotyping in Persuasive Communication: Influence Exerted by Disapproved Source [J]. Journal of Applied Social Psychology, 2004(34): 1192.

[9] M. Guirdham. Communicating Across Cultures [M]. West Lafayette: Purdue University Press, 1999: 163.

[10] Li Yafang. How to Realize the "Accessibility" Reading in International Communication - Taking the Communication Practice of Beijing Weekly as an Example [J]. Chinese Translation, 2015(5): 47.

[11] Lin Chongde. Psychology Dictionary [M]. Shanghai Education Publishing House, 2003(12). 